\title{
Differential price responses for tobacco consumption: implications for tax incidence
}

\author{
Guillermo Cruces, Guillermo Falcone, Jorge Puig
}

- Additional supplemental material is published online only. To view, please visit the journal online (http://dx.doi. org/10.1136/tobaccocontrol2021-056846).

CEDLAS, Centro de Estudios Distributivos, Laborales y Sociales, IIE-FCE, Universidad Nacional de La Plata, La Plata, Argentina

\section{Correspondence to}

Dr Guillermo Cruces, Economics, CEDLAS, La Plata 1900, Buenos Aires, Argentina; gcruces@cedlas.org

Received 12 June 2021 Accepted 11 December 2021

Check for updates

(c) Author(s) (or their employer(s)) 2022. No commercial re-use. See rights and permissions. Published by BMJ.

To cite: Cruces G, Falcone G, Puig J. Tob Control Epub ahead of print: [please include Day Month Year]. doi:10.1136/

tobaccocontrol-2021-056846

\section{ABSTRACT}

Increasing tobacco taxes is considered the most effective an cost-effective policy to reduce tobacco consumption. However, a common objection to tobacco taxes is that they tend to rely disproportionately on the poorest individuals since less affluent smokers incur proportionately greater expenditures on cigarettes compared with more affluent smokers. Such objections usually assume that all smokers throughout the income distribution react similarly to an increase in tobacco prices. But, if less affluent smokers are more sensitive to price changes (ie, they have a higher demand price elasticity), reductions in tobacco consumption should be higher at the bottom of the income distribution. This paper uses data from Argentina's Household Expenditure Survey to estimate demand price elasticities for tobacco by income and age groups. Results indicate that less affluent smokers present higher demand price elasticities for cigarettes than more affluent ones. A 10\% increase in cigarette prices would decrease consumption by $8.5 \%(4.4 \%)$ for the poorest (richest) smokers. In addition, young people are the most elastic group. These differential elasticities have relevant implications in terms of the distributional incidence of increasing tobacco taxes. As less well-off individuals reduce consumption relatively more, they bear a relatively lower tax burden. Thus, tobacco tax increases may not be regressive as is often believed. As a whole, this paper provides policymakers with relevant arguments for policy discussion and the public debate on common objections to increasing tobacco taxes.

\section{INTRODUCTION}

Tobacco use imposes high economic costs in terms of direct medical care as well as losses in productivity. ${ }^{1}$ To achieve the goal of reducing by $30 \%$ tobacco consumption by 2025, governments around the world implement tobacco control policies, including regulations to protect the public from tobacco smoke, programmes to assist those looking to quit, awareness campaigns that publicise the dangers of tobacco, advertising bans and increased taxes on tobacco products. Although increasing tobacco taxes is the single most costeffective instrument to reduce smoking, it is the least adopted. ${ }^{12}$ Particularly, the WHO's guide on best practices recommends that total taxes on tobacco products should be at least $75 \%$ of the retail price, but this suggestion is rarely implemented. ${ }^{1}$

Vast worldwide evidence shows that tax increases that effectively increase tobacco products' retail price make them less affordable, ${ }^{2}$ and generate large reductions in smoking prevalence and premature mortality. ${ }^{3}$ However, a common objection to tobacco taxes is that they tend to rely disproportionately on the poorest individuals since less affluent smokers incur proportionately greater expenditures on cigarettes compared with more affluent smokers. ${ }^{4}$ This is the classic observation on the regressivity of higher tobacco taxes. However, this reasoning implies a faulty assumption: that all individuals across the income distribution equally react to price changes, or in other words, exhibit the same demand price elasticity for tobacco products (eg, cigarettes). Nevertheless, if individuals react differently, the result of regressivity may not hold. Those individuals with higher elasticity will decrease consumption relatively more against price hikes. Thus, they will bear relatively less tax burden. If those individuals are the less affluent, then a tax increase may not be regressive at all.

This paper contributes to this debate and discusses the common objection of regressivity with an empirical application for Argentina, a developing country in Latin America. First, by estimating demand price elasticities for cigarettes by income level, based on household's survey data. We use a two-stage methodology that differentiates between two types of decisions: smoking or not; and the number of cigarettes consumed by smokers. Results show that demand price elasticities for cigarettes differ significantly among individuals. Specifically, while the elasticity for a person with an average income is -0.65 , this value is -0.85 for someone in the poorest decile of income. An individual in the richest decile has an elasticity of -0.44 . Thus, a $10 \%$ increase in cigarette prices would decrease consumption by $8.5 \%$ (4.4\%) for the poorest (richest) smokers. In addition, we estimate demand price elasticities for cigarettes by age groups. This is relevant since young people tend to have a greater sensitivity to changes in cigarette prices because they have lower levels of addiction-and also have less income-than other age groups. ${ }^{5}$ Thus, tobacco taxes could be a very effective tool to lower hazards of starting smoking in youth. Results indicate that young people (15-24 years) are the most sensitive to changes in cigarette prices. A $10 \%$ increase in the price of cigarettes would decrease consumption by $7.7 \%(4.5 \%)$ for young (old) individuals.

Second, using the estimated elasticities, we analyse their implications for the distributional incidence of increasing tobacco taxes. Specifically, we simulate the change in tobacco expenditures against a tax hike by individuals depending on their demand price elasticity. We assume first that all consumers have the same price elasticity and second that consumers have an income group-specific price elasticity. Results indicate that tobacco tax increases are regressive only under the first assumption. 
Under income group-specific price elasticity, the regressivity result seems to vanish.

\section{Related literature and contribution}

There exists abundant literature on the price elasticity of demand for tobacco products, mostly for high-income countries (HICs) and for low-income and middle-income countries (LMICs). ${ }^{4}$ In HICs, price elasticity ranges from -0.2 to -0.5 , with most clustered around -0.4. In LMICs, is at least as responsive, and often more responsive, to prices than in HICs. ${ }^{6}$ For example, Selvaraj et $a l^{7}$ remark that estimates from LMICs range from -0.50 to -1.00 . NCI-WHO ${ }^{8}$ indicates that most estimates fell between -0.2 and -0.8 . For Latin American and Caribbean (LAC) countries, price elasticity is likely below $-0.5,{ }^{9}$ but some studies support higher values. Paraje et $a l^{10}$ find -0.77 for El Salvador; Chavez ${ }^{11}-0.87$ for Ecuador; and Gonzalez-Rozada and Ramos-Carbajales ${ }^{12}-0.73$ for Peru. Evidence for Argentina can be found in Gonzalez-Rozada ${ }^{13}$; Martinez et al ${ }^{14}$; RodríguezIglesias et $a l^{15}$ and Gonzalez-Rozada. ${ }^{16}{ }^{17}$ Long-term price elasticity of cigarette ranges between -0.26 and -0.44 . Short-term price elasticity ranges between -0.15 in Martinez et $a l^{14}$ and -0.91 in Gonzalez-Rozada. ${ }^{16}$ In this context, we contribute by complementing previous findings with an average elasticity that is within the range of estimates available for the region.

Differential elasticities are supported when grouping individuals by income level or age. Lower-income groups are usually more price responsive than higher-income groups. ${ }^{4818}$ For Argentina, Gonzalez-Rozada ${ }^{17}$ finds a price elasticity of -0.35 $(-0.21)$ for the poorest (richest) individuals. Among all the contributions for Argentina, Gonzalez-Rozada ${ }^{17}$ is the only one that uses microdata from household surveys. He uses Global Adult Tobacco Survey for the year 2012 combined with the same methodology of our paper. Nargis et $a l^{19}$ for Bangladesh support that the elasticity for people belonging to lower (higher) socioeconomic status is $-0.75(-0.36)$. Similar results are documented by Selvaraj et $a l^{7}$ for India and $\mathrm{Choi}^{20}$ for Korea. In line with evidence for LMICs, evidence for Latin American countries can be found in Centro de Investigación Económica y Presupuestaria, ${ }^{21}$ Centro de Investigación en Alimentación Y Desarrollo, ${ }^{22}$ Instituto de Estudios Peruanos ${ }^{23}$ and Universidade Católica de Brasília. ${ }^{24}$ Based on different empirical studies, Verguet et $a l^{4}$ support the idea that price elasticity could vary within -1.0 to -0.2 for poor and rich individuals, respectively. In this context, our findings regarding price elasticities by income groups are in line with existing literature. In addition, young people are usually more responsive than older adults to changes in the prices of tobacco products. ${ }^{4}$ Empirical evidence suggests that total demand price elasticity for cigarettes is -2.11 among youth ${ }^{25} 26$ while -0.53 among adults. ${ }^{27}$ A relevant and closely related contribution for LAC countries is Guindon et $a l^{28}$ studying the relation between cigarette prices and smoking onset (ie, the transition between never smoking and smoking) among Chilean youths. Findings suggest that higher prices were associated with lower hazards of starting smoking. To the best of our knowledge, our findings regarding price elasticities by age groups are novel since Argentina does not currently have evidence in this regard.

The role of income group-specific price elasticities in terms of distributional incidence of tobacco taxes has been examined by several studies. Remler ${ }^{29}$ qualitatively demonstrates that a tax increase can be progressive for certain income gradients in price elasticity of demand for tobacco. Recently, Verguet et al developed a mathematical model and find that for sufficiently large price elasticity of demand for tobacco, the distribution in net cigarette expenditures could be progressive. The trend toward more progressive tobacco taxes may be exacerbated when taking into account the long-run effects of a tax increase. ${ }^{30}$ For example, if higher taxes discourage consumption, households can expect to save on future medical expenses associated with smokingrelated diseases, and they can also expect an increase in lifetime earnings due to a lower risk of premature death. As lowerincome households consume relatively more tobacco, savings in medical expenses and increases in future labour income will be relatively greater for them. When these factors are considered, the result of the regressivity of increasing tobacco taxes may vanish even further. ${ }^{31}$ In this context and even when we do not consider long-run effects, our results are a novel contribution for the Argentine case, since several studies that previously examine the distributional incidence of taxes in Argentina support the regressivity of tobacco taxes. ${ }^{32}$

\section{DATA}

We use data from the National Survey of Household Expenditures (ENGHo) conducted by the National Institute of Statistics and Census. The ENGHo provides information on tobacco consumption at the individual level for all towns of at least 5000 inhabitants. We use the wave corresponding to the years 2004 and 2005 (ENGHo 2004/2005). Although a new wave of this survey is available (ENGHo 2012/2013), we do not use it given the high rate of non-response, and a lack of adequate documentation to evaluate, among other things, the input procedures of household expenses. ${ }^{33}$ Data on tobacco expenditure and quantities are collected through a personal questionnaire and are self-reported by all individuals older than 10 years. For those younger than 10 years, the information is reported by an adult in charge. Table 1 shows descriptive statistics related to cigarette consumption by decile of household per capita income. The prevalence of cigarette consumption was-on average-approximately 32\%. Less affluent smokers incur proportionately greater expenditures on cigarettes and consume fewer packs compared with more affluent smokers. The price per pack paid by more affluent smokers is-on average-33\% higher than that paid by less affluent ones.

In Argentina, there are 9 million smokers (over a total population of 45 million inhabitants) and tobacco consumption causes 45000 deaths per year. ${ }^{34}$ Since 2011 , tobacco prevalence has diminished. According to the latest National Survey of Risk Factors, in 2018 the prevalence of cigarette consumption in the adult population was $22.2 \%, 7.5$ percentage points below the prevalence registered in 2005 . This prevalence was $26.1 \%$ for men and $18.6 \%$ for women, while the lowest prevalence was observed in the two age extremes (under 25 years and 65 years and over). According to the level of education, those with incomplete secondary level had a higher prevalence $(26.1 \%)$ than those with complete secondary and more (20.1\%). Consumption is mostly concentrated ( $97.2 \%$ of current smokers) on packs of manufactured cigarettes and presents few substitute products (eg, the consumption of bidis or gutka is not usual in Argentina). The country has one of the most affordable cigarettes in the world: internationally ranks 68 out of 176 countries, in terms of how cheap it is to consume cigarettes. ${ }^{35}$ In addition, it exhibits price dispersion between cheap and expensive brands. The share between the price of the cheapest brand in the price of the premium brand is $45.3 \%$, while for the LAC region is $62.1 \%$. $^{36}$ Illicit cigarette trade, after a relative decrease between 2005 and 2009, seems to have stabilised. ${ }^{37}$ Overall illicit tobacco trade 


\begin{tabular}{|c|c|c|c|c|c|}
\hline Decile & Prevalence (\%) & Share of household expenditure (\%) & Number of packs (units) & Price per pack (pesos per unit) & Household per capita income (pesos) \\
\hline 1 & 28.9 & 4.6 & 14.0 & 3.3 & 61.7 \\
\hline 2 & 32.2 & 2.5 & 15.6 & 3.5 & 116.3 \\
\hline 3 & 32.8 & 2.4 & 17.8 & 4.0 & 163.7 \\
\hline 4 & 36.4 & 2.4 & 18.7 & 3.8 & 212.3 \\
\hline 5 & 35.2 & 2.0 & 16.9 & 3.9 & 268.9 \\
\hline 6 & 30.0 & 1.5 & 18.9 & 4.0 & 337.8 \\
\hline 7 & 31.3 & 1.6 & 21.3 & 3.7 & 422.0 \\
\hline 8 & 32.7 & 1.4 & 21.7 & 4.0 & 542.5 \\
\hline 9 & 32.8 & 1.2 & 21.7 & 4.3 & 755.2 \\
\hline 10 & 31.4 & 0.8 & 22.1 & 4.4 & 1736.4 \\
\hline Average & 32.4 & 1.8 & 19.5 & 4.0 & 565.9 \\
\hline
\end{tabular}

Source: own elaboration using data from the ENGHo 2004/2005.

ENGHo, National Survey of Household Expenditures.

prevalence is estimated at $13.7 \%$, where $6.1 \%$ was attributable to stamp counterfeiting and $7.6 \%$ to contraband smuggling of foreign cigarette packs. ${ }^{38}$

As described in Gonzalez-Rozada, ${ }^{16}$ the tax structure on cigarette consumption in Argentina is very complex. Federal taxes affecting cigarettes are four ad-valorem taxes: (1) the additional emergency tax (IAE), with a rate of $7 \%$ over the retail price (RP); (2) the value-added tax (VAT) with a rate of $21 \%$; (3) the Special Tobacco Fund (FET) with a rate of $8.35 \%$; and (4) the internal tax (II), with an ad valorem rate of $70 \%$. The tax base of each one is different. For example, II is applied over RP excluding IAE, VAT and FET. VAT's base is RP excluding IAE, II and FET. Finally, FET is applied over RP excluding IAE and VAT. The province of Tierra del Fuego is exempted from the application of the internal tax law (which includes taxes on cigarettes) through the Industrial Promotion Regime (Law 19640). Thus, cigarettes are relatively cheaper there. One additional tax is levied at the subnational level: the turnover tax with an ad valorem rate that varies depending on the province. Tobacco tax collection was approximately US\$1.9 billion in 2020. This represents approximately $2 \%$ of total tax collection and $0.5 \%$ of Gross Domestic Product (GDP).

\section{METHODOLOGY}

We begin by estimating the demand for cigarettes using a twostage model. ${ }^{173940}$ The first stage models the decision to smoke (extensive margin), while the second stage estimates the number of cigarettes consumed by smokers (intensive margin). The prevalence equation defines the first stage and models the decision to smoke as follows:

$$
F_{i}=\beta_{0}+\beta_{1} p_{i}+\beta_{2} p_{i} Y_{i}+\beta_{3} Y_{i}+\beta_{4} Y_{i}^{2}+X^{\prime} \beta+\epsilon_{i}
$$

where $F_{i}$ is a binary variable that equals one if the individual $i$ smokes, and zero otherwise; $p_{i}$ is the logarithm of the unit price of cigarettes; $Y_{i}$ is the logarithm of the household per capita income; and the vector $X^{\prime}$ is composed of a set of observable characteristics at individual and at the household level. The first group includes age, squared age, gender and binary variables that indicate the highest educational level achieved, if the individual is a domestic employee and if the individual is unemployed. Variables at the household level include the logarithm of the household's per capita household income (and its square), the gender and maximum educational level of the household head, the presence of other smoking members, and the number of members in the household, by age: the number of infants (0-5 years), the number of children (6-14); the number of young people $(15-24)$, the number of adults $(25-64)$ and finally, the number of older persons $(+65)$. To account for the fact that individuals with different socioeconomic conditions may have different sensitivities to changes in the price of cigarettes, an interaction between individual household per capita income and the price of cigarettes (ie, $p_{i} Y_{i}$ ) is included. Note that the prices in the ENGHo 2004/2005 are approximated using the unit values (ie, expenditure over consumed quantity), which are imperfect substitutes of prices. Thus, according to Deaton ${ }^{41}$ and John, ${ }^{42}$ a few caveats are in place. First, these values are affected by the quality (ie, a pack of 20 cigarettes premium brand costs more than a pack of 20 cigarettes cheapest brand) and by where they are purchased (ie, small shop or fuel stations), which could vary across the country. There are also measurement errors, especially when some information (on quantity or expenditure) is missing for a given good. Second, the survey was not ex-ante designed to provide accurate price estimates.

As $F_{i}$ is binary, both probabilistic (probit) and linear probability models are estimated. From equation (1), the price elasticity of the participation in cigarette consumption is defined for the individual $i$ as: $\Omega_{i}^{\mathrm{p}}=\beta_{1}+\beta_{2} Y_{i}$. In a second stage, the number of cigarettes that smokers consume is modelled using the following consumption equation:

$$
C_{i}=\alpha_{0}+\alpha_{1} p_{i}+\alpha_{2} p_{i} Y_{i}+\alpha_{3} Y_{i}+\alpha_{4} Y_{i}^{2}+X^{\prime} \alpha+\epsilon_{i}
$$

where $C_{i}$ is the logarithm of the number of cigarettes consumed by individual $i$. The right-hand side variables are analogous to those for equation (1). Equation (2) also includes the interaction $p_{i} Y_{i}$ to account for price responsiveness for different income groups. The major difference in estimating the prevalence and consumption equations is the individuals included in each regression. While the first includes all individuals in the survey-smokers and non-smokers-the second one includes only those who report positive consumption of cigarettes. The price elasticity of cigarette consumption for individual $i$ is calculated as: $\Omega_{i}^{c}=\alpha_{1}+\alpha_{2} Y_{i}$. Thus, the total demand price elasticity for cigarettes for individual $i$ results as the sum of the prevalence and the consumption price elasticities: $\Omega_{i}^{\mathrm{t}}=\Omega_{i}^{\mathrm{p}}+\Omega_{i}^{\mathrm{c}}$.

The estimation of equation (1) presents two main challenges. First, a household survey only indicates the price paid for cigarettes by persons who smoke generating a potential sample selection problem. Second, prices can be a decision variable for individuals and not an exogenous variable. To address the first challenge, a price must be assigned for non-smoking individuals so as to include them in the first stage of the regression equation (if they are not included, the binary dependent variable would not have variability). Equation (3) is estimated to 
explain the price paid by smokers $(f)$ among a set of observable characteristics:

$$
p_{f}=\beta_{0}+X_{f}^{\prime} \beta+\epsilon_{f}
$$

where $p_{f}$ is the logarithm of the price of cigarettes paid by the smoker $f$ in the sample, and $X_{f}^{\prime}$ a vector of observable characteristics-similar to those included in $X^{\prime}$ in equations (1) and (2). Once the regression coefficients are estimated, the cigarette price for non-smoking individuals $(n f)$ is calculated according to observable characteristics and a random error from a normal distribution with the same deviation as $\epsilon_{f}: P_{n f}=\beta_{0}+\dot{X} n f \beta+\mu_{n f}$ . To address the second challenge (ie, endogeneity), we apply the instrumental variable (IV) method. The price that individual $i$ pays (or should pay) is instrumented with the average price of cigarettes in their province of residence, exploiting the spatial variability of the independent variable. This is a desirable approach to find an instrument because it assumes that the individual is a price taker and faces a 'market price'. ${ }^{17}$ Again, given the use of unit values, the spatial variability of the independent variable may reflect differences in prices (eg, those lower in the province of Tierra del Fuego given the tax exemption) but also differences associated with the limitations presented by the use of unit values, previously highlighted. In this way, the first stage of the IV method consists of a regression (equation 4) of the price paid for cigarettes (or imputed in the case of non-smokers) in province fixed effects, so as to exploit price variability that is only explained by spatial differences.

$$
p_{i}=\delta_{i} \text { Province }_{i}+\epsilon_{i}
$$

The interaction of the price and income must be instrumented analogously. In a second stage, equations (1) and (2) are estimated using only the variation in the price that can be explained by regional (exogenous) differences in cigarette prices.

To calculate elasticities by age group, the population is divided into four segments: young people (15-24), young adults (25-44), adults (44-64) and elderly persons (65+). Estimation is analogous to the process described for income deciles, but the interaction term is replaced with an interaction between price and age. Then, elasticities are calculated for the average age of each subgroup separately. As before, the prevalence equation is estimated with both probit and linear probability models.

Finally, we test the implications of differential elasticities by income deciles on the distributional incidence of tobacco taxes. Specifically, we simulate the change in tobacco expenditures by individuals depending on their cigarette consumption and their price elasticity (ie, income-share accounting definition). We first assume that all consumers have the same demand price elasticity. We then assume that consumers have an income group-specific price elasticity. In order to analyse the relative change in tobacco expenditure (relative to income), a 20\% increase in cigarette prices is simulated. This change is not arbitrary since it is similar to the change in the price of cigarettes that Argentina experienced after its recent changes in tobacco taxes. ${ }^{16}$ And it is also similar to that simulated by contributions related to our paper. ${ }^{31}$

\section{RESULTS}

\section{Estimate of elasticities by income and age groups}

Table 2 presents the price elasticity of demand for cigarettes by income deciles. In panel $\mathrm{A}$, the prevalence equation is estimated using a probit model. The prevalence and consumption regressions are presented in online supplemental tables A1 and A2. The total demand price elasticity for cigarettes is higher (in absolute value) for the poorest deciles. While the elasticity for an individual in the highest income decile is -0.44 , for an individual from the poorest decile is -0.85 . The price elasticity for an individual with an average income is -0.65 , within the range of price elasticity estimates available for LAC countries. Considering these results, a $10 \%$ increase in the price of cigarettes would decrease consumption by $8.5 \%(4.4 \%)$ for the poorest (richest) individuals. In line with Gonzalez-Rozada, ${ }^{17}$ our estimates suggest that the same increase reduces the number of smokers by $0.29 \%$, on average. In panel B, the prevalence equation is estimated using a linear model of probability. Again, the total demand price elasticity for cigarettes is higher for the poorest deciles suggesting that results are robust to this alternative estimation. In this case, a $10 \%$ increase in the price of cigarettes would decrease consumption by $7.8 \%(4.6 \%)$ for the poorest (richest) individuals. Since poorer smokers are more sensitive to changes in price than richer ones, as the tobacco tax increases, the smoking prevalence and consumption gap between different income groups decrease. Thus, a tobacco tax increase could not be a regressive policy, as usually emerges when a uniform price elasticity is assumed. We will inquire about this in the next subsection.

Table 3 presents the results on demand price elasticity by age group. A greater elasticity for cigarettes among young people can be appreciated. Specifically, the group of young people aged $15-25$ years presents an elasticity of -0.77 while the group of elderly individuals $(65+$ years) presents an elasticity of -0.45 .

Table 2 Demand price elasticities of cigarettes in Argentina, by deciles of household per capita income: prevalence, consumption and total

\begin{tabular}{|c|c|c|c|c|c|c|}
\hline \multirow[b]{2}{*}{ Decile } & \multicolumn{3}{|c|}{ Panel A: probit in prevalence } & \multicolumn{3}{|c|}{ Panel B: linear probability model in prevalence } \\
\hline & Prevalence & Consumption & Total price elasticity & Prevalence & Consumption & Total price elasticity \\
\hline 1 & $-0.084(0.0615)$ & $-0.765^{* * *}(0.0068)$ & $-0.849 * * *(0.0546)$ & $-0.016(0.0171)$ & $-0.765^{* * *}(0.0068)$ & $-0.781 * * *(0.0103)$ \\
\hline 2 & $-0.063^{*}(0.0367)$ & $-0.707^{* * *}(0.0087)$ & $-0.769 * * *(0.0281)$ & $-0.012(0.0103)$ & $-0.707^{* * *}(0.0087)$ & $-0.719 * * *(0.0017)$ \\
\hline 3 & $-0.051 * *(0.0236)$ & $-0.675^{* * *}(0.0097)$ & $-0.726 * * *(0.0139)$ & $-0.01(0.0067)$ & $-0.675^{* * *}(0.0097)$ & $-0.685^{* * *}(0.003)$ \\
\hline 4 & $-0.042^{* * *}(0.0133)$ & $-0.65 * * *(0.0105)$ & $-0.692 * * *(0.0029)$ & $-0.009^{* *}(0.0038)$ & $-0.65^{* * *}(0.0105)$ & $-0.659 * * *(0.0066)$ \\
\hline 5 & $-0.033^{* * *}(0.0042)$ & $-0.628^{* * *}(0.0111)$ & $-0.662 * * *(0.0069)$ & $-0.007^{* * *}(0.0013)$ & $-0.628^{* * *}(0.0111)$ & $-0.636 * * *(0.0098)$ \\
\hline 6 & $-0.026 * * *(0.0045)$ & $-0.607^{* * *}(0.0119)$ & $-0.633^{* * *}(0.0164)$ & $-0.006^{* * *}(0.0011)$ & $-0.607^{* * *}(0.0119)$ & $-0.613 * * *(0.013)$ \\
\hline 7 & $-0.018(0.0133)$ & $-0.587^{* * *}(0.0125)$ & $-0.604 * * *(0.0258)$ & $-0.005(0.0035)$ & $-0.587^{* * *}(0.0125)$ & $-0.591 * * *(0.016)$ \\
\hline 8 & $-0.009(0.0233)$ & $-0.562^{* * *}(0.0133)$ & $-0.571 * * *(0.0366)$ & $-0.003(0.0063)$ & $-0.562 * * *(0.0133)$ & $-0.565 * * *(0.0195)$ \\
\hline 9 & $0.003(0.0363)$ & $-0.531 * * *(0.0144)$ & $-0.528 * * *(0.0507)$ & $-0.001(0.0099)$ & $-0.531 * * *(0.0144)$ & $-0.532 * * *(0.0242)$ \\
\hline 10 & $0.028(0.0639)$ & $-0.465^{* * *}(0.0166)$ & $-0.437 * * *(0.0806)$ & $0.003(0.0175)$ & $-0.465^{* * *}(0.0166)$ & $-0.461^{* * *}(0.0341)$ \\
\hline Average & $-0.029 * * *(0.0001)$ & $-0.618^{* * *}(0.0116)$ & $-0.647^{* * *}(0.0117)$ & $-0.007^{* * *}(0.0001)$ & $-0.618^{* * *}(0.0116)$ & $-0.624 * * *(0.0115)$ \\
\hline
\end{tabular}
elasticities

Source: own elaboration using data from the ENGHo 2004/2005, INDEC. Note: SEs in parentheses, calculated using bootstrap, with 100 repetitions. Statistical significance ${ }^{* * *} \mathrm{p}<0.01$, ${ }^{*} \mathrm{p}<0.05$, ${ }^{*} \mathrm{p}<0.1$.

ENGHo, National Survey of Household Expenditures; INDEC, National Institute of Statistics and Census. 
Table 3 Demand price elasticities of cigarettes in Argentina, by age groups: prevalence, consumption and total elasticities

\begin{tabular}{|c|c|c|c|c|c|c|}
\hline \multirow[b]{2}{*}{ Age group } & \multicolumn{3}{|c|}{ Panel A: probit in prevalence } & \multicolumn{3}{|c|}{ Panel B: linear probability model in prevalence } \\
\hline & Prevalence & Consumption & Total price elasticity & Prevalence & Consumption & Total price elasticity \\
\hline$(15-24)$ & $-0.065^{* * *}(0.0034)$ & $-0.702 * * *(0.003)$ & $-0.767^{* * *}(0.0063)$ & $-0.011^{* *}(0.0007)$ & $-0.702^{* * *}(0.003)$ & $-0.713 * * *(0.0037)$ \\
\hline$(25-44)$ & $-0.041^{* * *}(0.0007)$ & $-0.643^{* * *}(0.0082)$ & $-0.684 * * *(0.0089)$ & $-0.009 * *(0.000)$ & $-0.643^{* * *}(0.0082)$ & $-0.651 * * *(0.0083)$ \\
\hline$(45-64)$ & $-0.009^{* *}(0.003)$ & $-0.561^{* * *}(0.0154)$ & $-0.571 * * *(0.0124)$ & $-0.005^{* * *}(0.0008)$ & $-0.561^{* * *}(0.0154)$ & $-0.566 * * *(0.0146)$ \\
\hline$(+65)$ & $0.024(0.0068)$ & $-0.478^{* * *}(0.0228)$ & $-0.454 * * *(0.016)$ & $-0.002 * * *(0.0017)$ & $-0.478^{* * *}(0.0228)$ & $-0.479 * * *(0.0211)$ \\
\hline Average & $-0.029(0.0007)$ & $-0.612 * * *(0.0109)$ & $-0.641^{* * *}(0.0103)$ & $-0.007^{* * *}(0.0003)$ & $-0.612 * * *(0.0109)$ & $-0.619 * * *(0.0107)$ \\
\hline
\end{tabular}

Source: own elaboration using data from the ENGHo 2004/2005, INDEC. Note: SEs in parentheses, calculated using bootstrap, with 100 repetitions. Statistical significance ${ }^{* * *} \mathrm{p}<0.01$, ${ }^{* *} \mathrm{p}<0.05,{ }^{*} \mathrm{p}<0.1$.

ENGHo, National Survey of Household Expenditures; INDEC, National Institute of Statistics and Census.

The average elasticity of -0.65 is consistent with the results calculated by income levels. Considering these results, a $10 \%$ increase in the price of cigarettes would decrease consumption by $7.7 \%(4.5 \%)$ for young (old) individuals. To the best of our knowledge, this is novel evidence since Argentina does not currently have evidence in this regard.

\section{Differential elasticities: implications for tax incidence}

As was shown in table 1 , less affluent smokers incur proportionately greater expenditures on cigarettes compared with more affluent smokers. Thus, the higher tax burden associated with a tax increase will represent a larger income share of less well-off individuals. This is the classic result on the regressivity of increasing tobacco taxes. However, our estimates of demand price elasticities suggest that not all individuals react in the same way to changes in cigarette prices. Less affluent smokers reduce tobacco consumption relatively more than more affluent ones. Consequently, less affluent smokers will decrease consumption relatively more against price hikes, and they will bear relatively less tax burden. In this context, a tax increase may not be regressive at all.

To test these implications, we simulate the change in tobacco expenditure for individuals depending on their cigarette consumption and their price elasticity. We first assume that all consumers have the same price elasticity of demand. We then assume that consumers have an income group-specific price elasticity. Figure 1 shows the proportional change in cigarette expenditure given the simulated price increase (ie, income-share accounting definition), using the average elasticity estimated in table 2 (ie, -0.65). This effect is called the average effect, given that all individuals react according to the average elasticity. Under this assumption, an increase in the price of cigarettes due to a tax hike would be regressive as it disproportionately

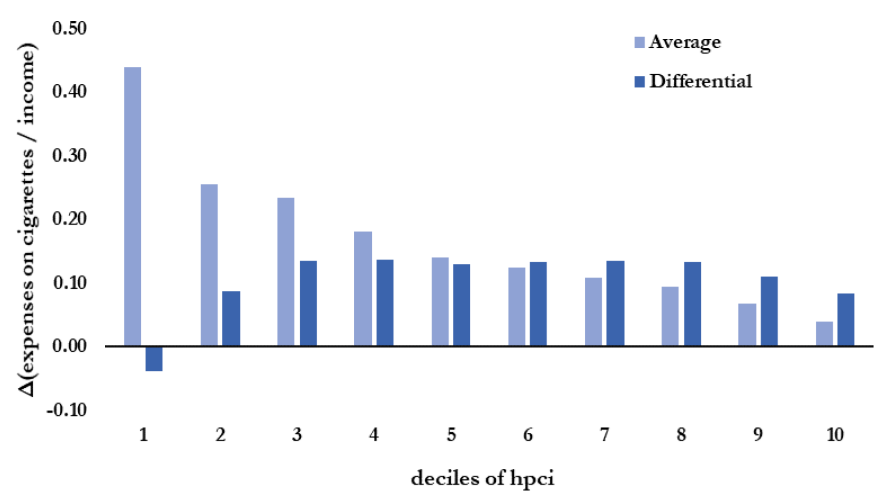

Figure 1 Distributional incidence of increasing tobacco taxes in Argentina. Change in expenditure on cigarettes as a share of income. In percentage points by deciles of household per capita income (hpci). Source: own elaboration using data from the ENGHo 2004/2005, INDEC. affects the expenditures of less affluent smokers. In particular, a $20 \%$ increase in the price of cigarettes has an effect 11 times greater for the poorest decile compared with the richest decile. The poorest (richest) decile would increase its tobacco expenditures-as a share of income-by $0.44(0.04)$ percentage points.

Alternatively, figure 1 also shows the proportional change in cigarette expenditure given the simulated price increase but using the income group-specific price elasticity (also estimated in table 2). This effect is called the differential effect. The result on the regressivity of increasing tobacco taxes seems to vanish. Now, against a $20 \%$ increase in the price of cigarettes, the poorest decile would reduce its proportion of tobacco spending in relation to income by -0.04 percentage points, while the richest decile would increase it by 0.08 . It should be noted that given the magnitude of the simulated price change (ie, 20\%), expenditure may fall due to the presence of a second-order effect given by the full differential. In all cases, elasticities are those presented in panel A (probit estimation in prevalence), table 2, but similar results can be found with elasticities corresponding to panel $\mathrm{B}$. Thus, the assumption on the price elasticity of demand for tobacco products shows strong policy implications in terms of tobacco tax incidence.

\section{CONCLUSIONS}

This paper contributes to the discussion about the regressivity of increasing tobacco taxes. For this purpose, we estimate income group-specific and age-specific demand price elasticities for Argentina, and then analyse their implications in terms of the distributional incidence of increasing tobacco taxes. Results indicate that less affluent smokers present higher demand price elasticities for cigarettes than those more affluent ones. Specifically, the elasticity for a person with an average income in Argentina is -0.65 , which is within the range of estimates available for the region. However, this value is $-0.85(-0.44)$ for a person with the average income of the poorest (richest) decile. In addition, we find that young people are the most elastic group for cigarette price changes. This evidence is novel since Argentina does not present estimates on tobacco price elasticities by age group. When analysing the implications of income group-specific demand price elasticities for distributional incidence, we show that tobacco tax increases are not regressive as is often believed. As less well-off individuals reduce consumption relatively more against price increases-induced by higher taxes-, they bear a relatively lower tax burden.

The relevance of the differential elasticities in terms of distributional incidence of increasing tobacco taxation could become even more important if further long-run effects (not studied in this paper) are also considered. For example, savings on future medical expenses or an increase in lifetime earnings due to a lower risk of premature death. ${ }^{3031}$ 
As a whole, this paper contests the traditional view of tax regressivity ${ }^{4}$ and provides relevant arguments for policy discussion and the public debate on common objections to increasing tobacco taxes.

\section{What this paper adds}

- Increasing tobacco taxes is an effective and cost-effective policy to reduce consumption. However, this measure has been pointed out as regressive because the price increase would affect more poorer individuals.

- The real impact of higher tobacco prices depends on which consumers react more to price changes (have a higher price elasticity).

- Using Argentina's Household Expenditure Survey, we show that poorer and younger individuals are more sensible to price changes compared with richer and older individuals.

- Our estimates imply that increasing tobacco taxes is not a regressive policy as it is often mistakenly argued, and it is also a very effective measure to lower hazards of starting smoking in youth.

\section{Twitter Guillermo Falcone @guille_falcone and Jorge Puig @puigjorge}

Acknowledgements We would like to thank the editor (Guillermo Paraje) for his guidance and useful comments that substantially improve our paper. Also, we thank German Rodriguez Iglesias, Irene Brambilla, Santiago Afonso, and two anonymous reviewers for helpful comments and discussion.

Contributors GC, JP and GF conceptualized the study, conducted the statistical analysis, and interpreted the findings. GC, JP and GF wrote the article. GC is the guarantor of the study.

Funding The authors have not declared a specific grant for this research from any funding agency in the public, commercial or not-for-profit sectors.

Competing interests None declared.

Patient consent for publication Not required.

Ethics approval This study does not involve human participants.

Provenance and peer review Not commissioned; externally peer reviewed.

Data availability statement Data are available upon reasonable request. Data were drawn from a household survey. They are available upon request.

ORCID ID

Jorge Puig http://orcid.org/0000-0001-5033-5608

\section{REFERENCES}

1 World Health Organization. WHO report on the global tobacco epidemic 2015: raising taxes on tobacco. World Health Organization, 2015.

2 World Health Organization. WHO technical manual on tobacco tax policy and administration. Geneva: World Health Organization, 2021.

3 Ferrante D, Levy D, Peruga A, et al. The role of public policies in reducing smoking prevalence and deaths: the Argentina tobacco policy simulation model. Rev Panam Salud Publica 2007:21:37-49.

4 Verguet S, Kearns PKA, Rees VW. Questioning the regressivity of tobacco taxes: a distributional accounting impact model of increased tobacco taxation. Tob Control 2021;30:245-57.

5 Joseph RA, Chaloupka FJ. The influence of prices on youth tobacco use in India. Nicotine Tob Res 2014;16 Suppl 1:S24-9.

6 Chaloupka FJ, Yurekli A, Fong GT. Tobacco taxes as a tobacco control strategy. Tob Control 2012;21:172-80.

7 Selvaraj S, Srivastava S, Karan A. Price elasticity of tobacco products among economic classes in India, 2011-2012. BMJ Open 2015;5:e008180.

8 U.S. National Cancer Institute, World Health Organization (NCI-WHO). The economics of tobacco and tobacco control, 2016.

9 Guindon GE, Paraje GR, Chaloupka FJ. The impact of prices and taxes on the use of tobacco products in Latin America and the Caribbean. Am J Public Health 2015;105:e9-19.

10 Paraje G, Araya D, De Paz A, et al. Price and expenditure elasticity of cigarette demand in El Salvador: a household-level analysis and simulation of a Tax increase. Tob Control 2021;30:422-7.
11 Chávez R. Elasticidad precio de la demanda de cigarillos Y alcohol en Ecuador Con datos de hogares. Rev Panam Salud Publica 2016;40:222-8.

12 Gonzalez-Rozada M, Ramos-Carbajales A. Implications of increasing cigarette taxes in Peru. DEP of Econ working papers. Universidad Torcuato Di Tella, 2016.

13 González-Rozada M. Economía del control del tabaco en Los países del Mercosur Y estados asociados: Argentina: 1996-2004. Washington, DC: PAHO, 2006.

14 Martinez E, Mejia R, Pérez-Stable EJ. An empirical analysis of cigarette demand in Argentina. Tob Control 2015;24:89-93.

15 Rodríguez-Iglesias G, Schoj V, Chaloupka F, et al. Analysis of cigarette demand in Argentina: the impact of price changes on consumption and government revenues. Salud Publica Mex 2017;59:95-101.

16 González-Rozada M. Impact of a recent tobacco tax reform in Argentina. Tob Control 2020;29:5300-3.

17 Gonzalez-Rozada M. Increasing cigarette taxes is unfair to the poor? Evidence from Argentina. DEP of Econ working papers. Universidad Torcuato Di Tella, 2019.

18 Farrelly MC, Bray JW, Pechacek T. Response by adults to increases in cigarette prices by sociodemographic characteristics. South Econ J 2001;68:156-65.

19 Nargis N, Ruthbah UH, Hussain AKMG, et al. The price sensitivity of cigarette consumption in Bangladesh: evidence from the International tobacco control (ITC) Bangladesh wave 1 (2009) and wave 2 (2010) surveys. Tob Control 2014;23 Suppl 1:i39-47.

20 Choi SE. Are lower income smokers more price sensitive?: the evidence from Korean cigarette tax increases. Tob Control 2016;25:141-6.

21 Centro de Investigación Económica y Presupuestaria A.C. (CIEP). Extended costbenefit analysis of tobacco consumption in Mexico. Tobacconomics Research Report, 2020.

22 Centro de Investigación en Alimentación Y Desarrollo (CIAD). Analysis of tobacco taxation and simulations in Mexico using LATINMOD. Tobacconomics research report, 2020. Available: https://tobacconomics.org/research/analysis-of-tobacco-taxationand-simulations-in-mexico-using-latinmod/

23 Instituto de Estudios Peruanos (IEP). Cost-benefit analysis of tobacco consumption in Peru. Tobacconomics Research Report, 2020.

24 Universidade Católica de Brasília (UCB). An extended cost-benefit-analysis of tobacco taxation in Brazil. Tobacconomics Research Report, 2020.

25 Kostova D, Ross H, Blecher E, et al. Is youth smoking responsive to cigarette prices? Evidence from low- and middle-income countries. Tob Control 2011;20:419-24.

26 Nikaj S, Chaloupka FJ. The effect of prices on cigarette use among youths in the global youth tobacco survey. Nicotine Tob Res 2014;16 Suppl 1:S16-23.

27 Kostova D, Tesche J, Perucic A-M, et al. Exploring the relationship between cigarette prices and smoking among adults: a cross-country study of low- and middle-income nations. Nicotine Tob Res 2014;16 Suppl 1:S10-15.

28 Guindon GE, Paraje GR, Chaloupka FJ. Association of tobacco control policies with youth smoking onset in Chile. JAMA Pediatr 2019;173:754-62.

29 Remler DK. Poor smokers, poor quitters, and cigarette tax regressivity. Am J Public Health 2004:94:225-9.

30 Vulovic V, Chaloupka FJ. Questioning the regressivity of tobacco taxes: a distributional accounting impact model of increased tobacco taxation-commentary. Tob Control 2021;30:260-1.

31 Fuchs A, Meneses F. Are tobacco taxes really regressive? Evidence from Chile. The World Bank, 2017.

32 Fernández Felices D, Guardarucci I, Puig J. Incidencia distributiva del sistema tributario argentino. Universidad Nacional de La Plata, 2014.

33 INDEC. La medición de la pobreza Y La indigencia en Argentina. 2016. dT N ${ }^{\circ} 22$. Available: https://www.indec.gob.ar/ftp/cuadros/sociedad/EPH_metodologia_22_ pobreza.pdf

34 Alcaraz A, Hernández-Vásquez A, Palacios A, et al. Health and economic impact of health warnings and plain tobacco packaging in seven Latin American countries: results of a simulation model. Nicotine Tob Res 2020;22:2032-40.

35 World Health Organization. WHO report on the global tobacco epidemic 2021: addressing new and emerging products, 2021.

36 World Health Organization. WHO report on the global tobacco epidemic, 2019.

37 Paraje G. Illicit cigarette trade in five South American countries: a gap analysis for Argentina, Brazil, Chile, Colombia, and Peru. Nicotine Tob Res 2019;21:1079-86.

38 Pizarro ME, Giacobone G, Shammah C, et al. Illicit tobacco trade: empty pack survey in eight Argentinean cities. Tob Control 2021. doi:10.1136/ tobaccocontrol-2020-056405. [Epub ahead of print: 08 Apr 2021].

39 Colman GJ, Remler DK. Vertical equity consequences of very high cigarette Tax increases: if the poor are the ones smoking, how could cigarette tax increases be progressive? J Policy Anal Manage 2008;27:376-400.

40 Jones AM. A double-hurdle model of cigarette consumption. J Appl Econ 1989;4:23-39. doi:10.1002/jae.3950040103

41 Deaton A. Quantity, and spatial variation of price. Am Econ Rev 1988;78:418-30 http://www.jstor.org/stable/1809142

42 John RM. Price elasticity estimates for tobacco products in India. Health Policy Plan 2008:23:200-9. 